\title{
Research on meandering river reservoir deposition architecture and 3D modeling of the Gudao Oil field in the Bohai Bay Basin
}

\author{
Junwei Zhao ${ }^{1,2} \cdot$ Huaimin $\mathrm{Xu}^{3}$ - Gongyang $\mathrm{Chen}^{1} \cdot \mathrm{Cui} \mathrm{He}^{4} \cdot$ Dali Yue ${ }^{3}$. \\ Shenghe $\mathrm{Wu}^{3} \cdot$ Lifeng $\mathrm{Wen}^{5}$
}

Received: 5 July 2016/Accepted: 5 August 2017/Published online: 3 October 2017

(c) The Author(s) 2017. This article is an open access publication

\begin{abstract}
The distribution of remaining oil is controlled by internal sand body heterogeneity in the middle and late stages of oil field development. Reservoir architecture analysis has been conducted in the third sand group in the Guantao Formation of the Gudao Oil field. Different scales of reservoir architecture units have been identified, including complex meandering river belt, single meandering river belt, single point bar and inner point bar. Four different single channel signatures have been found in the
\end{abstract}

Junwei Zhao

zhaojunwei0201@126.com

Huaimin $\mathrm{Xu}$

wzxhm2015@126.com

Gongyang Chen

chen_gy1001@126.com

Cui $\mathrm{He}$

hecui_666@163.com

Dali Yue

3060545596@qq.com

Shenghe Wu

3014263625@qq.com

Lifeng Wen

1992559106@qq.com

1 Institute of Mud Logging Technology and Engineering, Yangtze University, Jingzhou 434023, China

2 Postdoctoral research workstation of Yangtze University, Jingzhou 434023, China

3 Department of Geoscience, China University of Petroleum (Beijing), Beijing 102249, China

4 Department of Energy Resources, China University of Geosciences (Beijing), Beijing 102249, China

5 Exploration and Production Research Institute, Sinopec, Beijing 100083, China research area to identify the single channel belt. The single point bar has been distinguished based on point bar development characteristics. The architecture of the inner point bar has been analyzed based on subsurface well data and empirical formulas. The lateral accretion angle of the muddy layer ranges from $5^{\circ}$ to $8^{\circ}$, the interspace between lateral accretion muddy layers ranges from 20 to $35 \mathrm{~m}$, and the horizontal width of a single lateral accretion sand body is $55-120 \mathrm{~m}$. Based on the above-mentioned reservoir architecture analysis, a reservoir architecture model has been established using the hierarchical modeling method. A three-dimensional porosity and permeability model has been developed within architecture model constraints and could provide a reliable geological template for oil field development and production.

Keywords Reservoir architecture - Meandering river . Reservoir modeling · Enhanced oil recovery

\section{Introduction}

Subsequent to many years of water injection development, most of the onshore oil fields in China went into high water cut, high recovery and high decline rate stages. Prediction and exploitation of remaining oil in reservoirs have become important assets of oil field work. Remaining oil is primarily controlled by reservoir and exploitation process heterogeneities (Wu et al. 2005). Many achievements have been made in reservoir heterogeneity research, which can, to a certain extent, improve reservoir recovery (Weber and Hans 1999; Qiu and Xue 2001). However, traditional reservoir research methods have been unable to meet the demand for oil field development and production. The distribution of remaining oil is controlled by internal sand body 
heterogeneities, such as the interface between genetic units in complex meandering river belts and lateral accretion layers inside point bars (Miall 1988; Makaske and Weerts 2005). More research on reservoir deposition architecture, which is crucial for oil field work, is warranted.

The concept of reservoir architecture was first proposed by Miall $(1985,1996)$. This term refers to the relationships between morphology, size, direction and overlapping of reservoir architecture units on different scales and characterizes qualitative and quantitative reservoir distribution. Many scholars have carried out research on quantitative relationships in meandering river reservoirs. Allen (1983), Schumm et al. (1972) and Leeder (1973) proposed a series of empirical formulas to calculate the distribution scale of fluvial face sand bodies influenced by ancient hydrology and geomorphology. Lorenz et al. (1985) and Gibling (2006) published articles regarding the relationship between thickness and width in channel sand bodies. It is important to study the distribution of ancient channel reservoirs. High-resolution ground penetrating radar (GPR) and drilling well data are used to obtain three-dimensional information on outcrop and modern deposition similar to the subsurface reservoir (Jiao et al. 2005; Makaske and Weerts 2005; Richard and Jones 2007; Matthew et al. 2008). Hence, spatial variation of reservoir architecture and lithofacies can be determined. However, while these studies have primarily focused on modern sedimentation and outcrop, there is a lack of research on subsurface reservoir characterization. Therefore, the study of underground meandering river reservoir architecture is of great importance. In the late period of oil field development, the research of reservoir architecture has great significance for remaining oil potential assessment and exploitation. Therefore, extensive analysis of the meandering river reservoir architecture in the third sand group of the Guantao Formation in the Gudao Oil field has been performed. A 3-D reservoir architecture model has been established using the architecture characterization results in the dense well network area. A reservoir parameter model has been developed within reservoir architecture model constraints, which could provide a reliable geological model for oil field exploitation.

\section{Geological background}

The Gudao Oil field is situated in Dongying City, Shandong Province, China (Fig. 1a). Regionally, this oil field is located in the eastern part of the Zhanhua Sag in the Jiyang depression of the Bohai Bay basin, which is a large-scale anticline reservoir (Fig. 1b). The study area Zhong1 is in the central part of the Gudao Oil field (Fig. 1c). Cenozoic strata, from below to above, include the Shahejie, Dongying, Guantao, Minghuazhen and Pingyuan Formations. The Guantao
Formation, a set of sand and mudstone strata at a depth of $1120-1350 \mathrm{~m}$, is one of the main oil-bearing reservoirs ( $\mathrm{Li}$ et al. 2002). Focus of this study is the third sand group in the Guantao Formation, $\mathrm{Ng} 3$, which is a typical meandering river sediment facies. The characteristics of the reservoir are high porosity, high permeability and strong heterogeneity. It can be divided into five thin layers: $\mathrm{Ng} 31, \mathrm{Ng} 32, \mathrm{Ng} 33, \mathrm{Ng} 34$ and $\mathrm{Ng} 35$. Ng34 and $\mathrm{Ng} 35$ can be subdivided into $\mathrm{Ng} 341, \mathrm{Ng} 342$, $\mathrm{Ng} 351$ and $\mathrm{Ng} 352$. Thin layers in the $\mathrm{Ng} 3$ sand group correspond to super-short sedimentary cycles, and the $\mathrm{Ng} 3$ sand group corresponds to the middle sedimentary cycle (Fig. 2).

Since exploitation in 1971, the Gudao Oil field experienced four main stages, including natural energy production stage, low water cut stage, medium water cut stage and high water cut stage. After more than 40 years of development, the overall water cut ratio of the Gudao Oil field has reached more than $90 \%$ ( $\mathrm{Su}$ et al. 2009). The distribution of remaining oil is complex; hence, it is necessary to study the meandering river reservoir architecture to determine the distribution potential of remaining oil and provide a geological basis for the oil field.

\section{Data and methodology}

For the research area, drilling and production data are in abundance, including well logging curves and sand body interpretation results of 338 wells in the dense well network area and six core wells data. Based on the abovementioned data, the sedimentary characteristics of the meandering river reservoir in the research area have been studied, a classification of meandering river reservoir architecture units has been performed, and a reservoir architecture model has been established.

\section{Results and discussion}

\section{Characteristics of deposition architecture units}

Analysis of meandering river reservoir architecture is divided into three levels. The first level is the complex meandering river belt scale, which is composed of multiple meandering river belts, including complex channel belt, overbank and floodplain; the second level is the genetic microfacies scale, including point bar, abandoned channel, natural levee, crevasse splay and crevasse channel; the third level is the inner point bar scale, primarily including lateral accretion sand body and lateral accretion layer.

The complex channel belt is composed of multiple channel belts stacked together in plane. A single channel belt is composed of several point bars. A channel is a water flowing tunnel in the alluvial environment in which the 


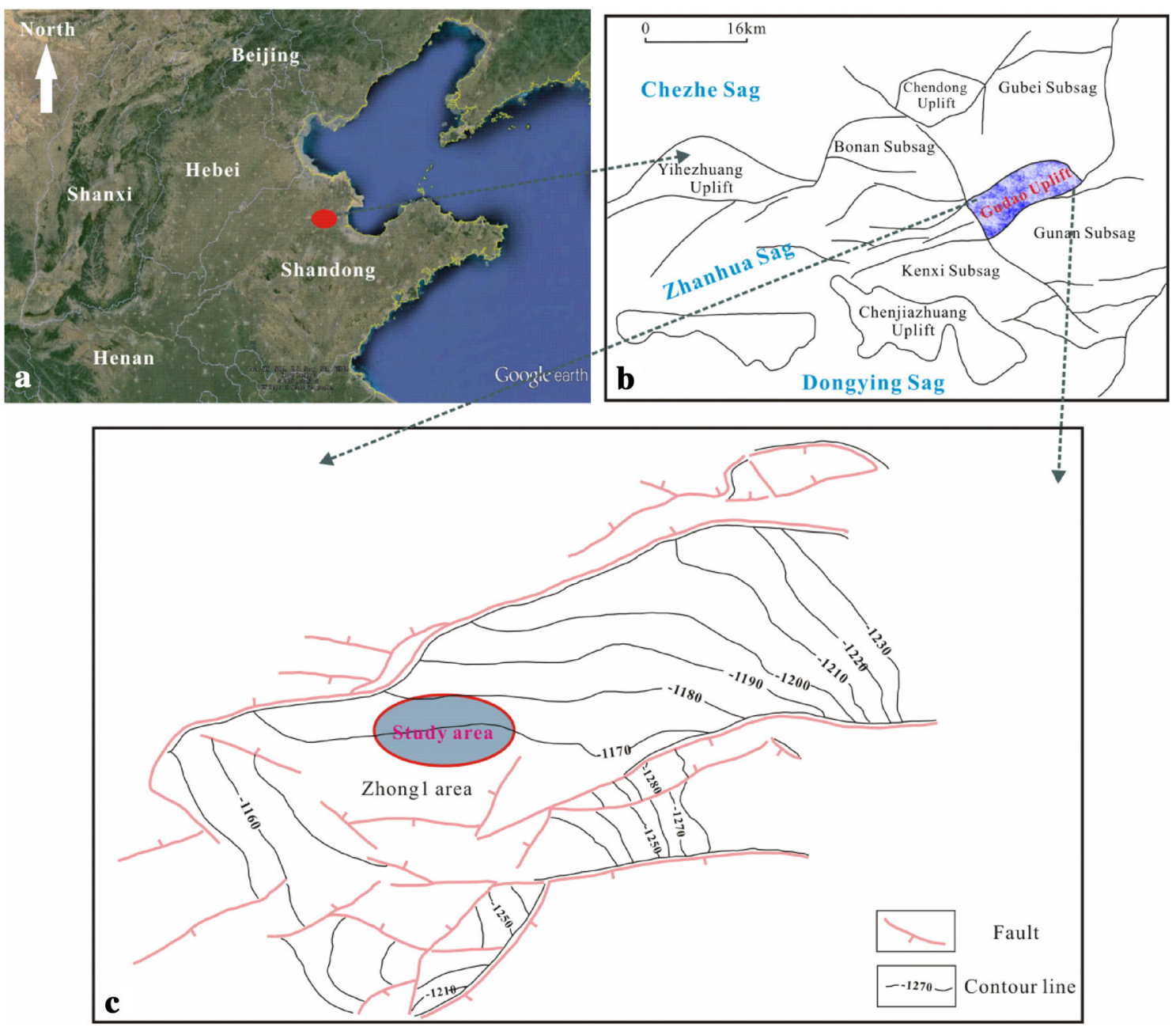

Fig. 1 Structural position map of the study area. a Location of Zhanhua sag in Jiyang depression in Bohai bay basin in China. b Location of Gudao uplift in Zhanhua sag. c Study of Zhong1 area in Gudao Oil field and the faults distribution in Gudao Oil field

channel can be filled by sand bodies such as channel lag and point bar deposits. The bottom of the channel sand body is the scouring surface, on which the gravel is deposited. During the formation of an abandoned channel, mainly fine-grained sediments are deposited. A single channel sand body is characterized by a positive rhythm of smaller grain size and smaller sedimentary structure directed vertically upward. From below to above, there are trough cross-bedding, parallel bedding and horizontal bedding. A single channel sand body has a dual structure, with the vertical thickness ranging from 2 to $10 \mathrm{~m}$ (Fig. 2). Overbank deposits include natural levee, crevasse splay, crevasse channel deposits, which mainly develop siltstone, and interbedded muddy siltstone and silty mudstone. The point bar is the main deposit part of the meandering river sand body, which is formed as a result of lateral accretion of river water flow (Xue 1991). The meandering river point bar sand body mainly consists of three elements: lateral accretion sand body, lateral accretion muddy layer and lateral accretion plane. The typical deposition model of point bars in humid environments is shown in Fig. 3. The lateral accretion muddy layer is horizontally and obliquely distributed. The lateral accretion muddy layer is the most important element of the point bar with the lithology in this area mainly being mudstone, silty mudstone and muddy siltstone.

\section{Division of single meandering river belt}

The frequent swing of the meandering river leads to a gradual increase in sand body width. The complex meandering river belt is composed of single overlapping meandering river belts, which were formed in different periods. Based on the idea of hierarchy analysis in architecture research of meandering river reservoirs, the single channel belt within the complex channel belt is divided first. Based on the establishment of the single channel qualitative distribution model, four types of single channel 
Fig. 2 Division of sedimentary cycles and the interpretation of meandering river architecture units in well 13XJ9 in Gudao Oil field

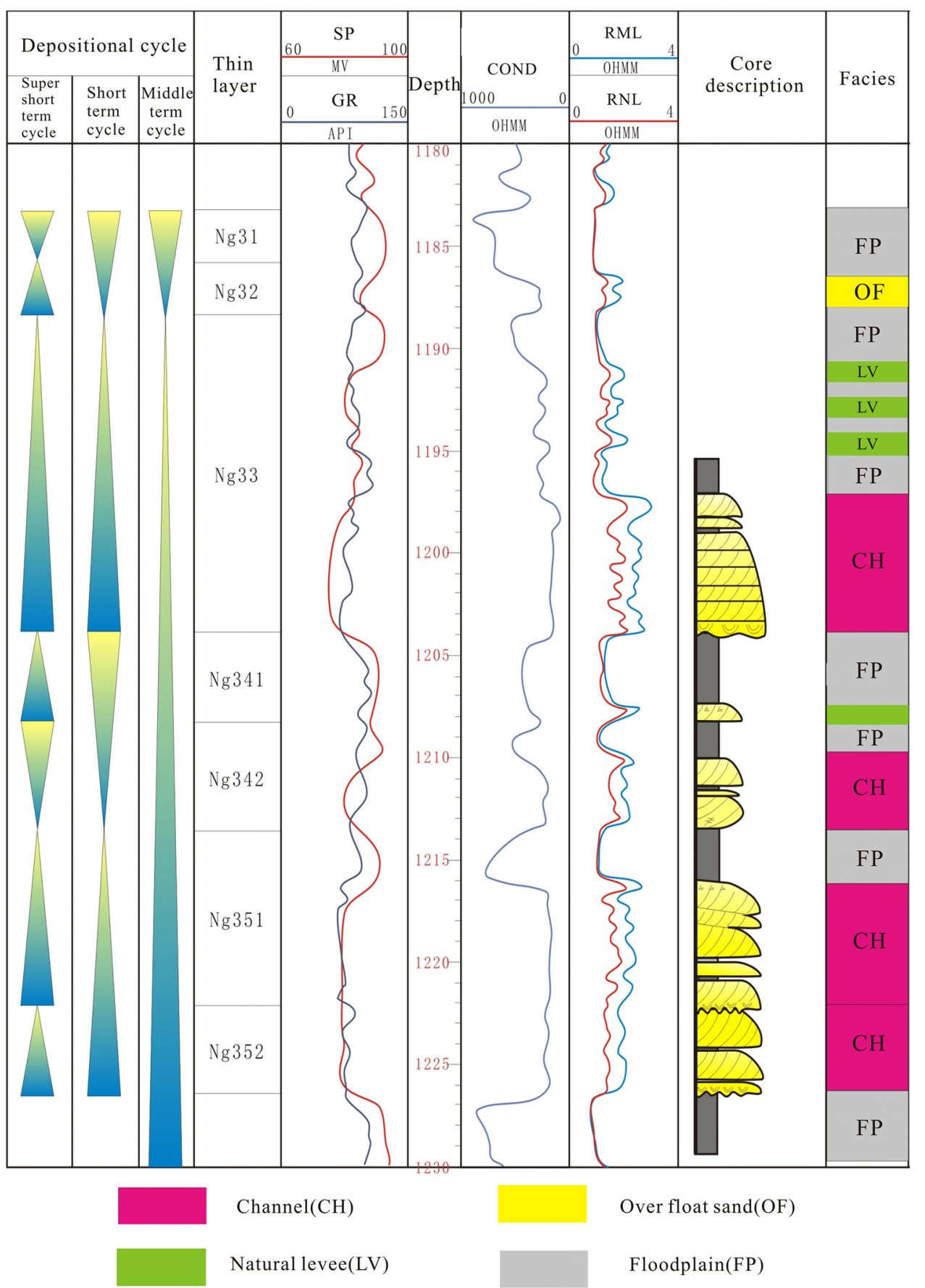

Fig. 3 Typical deposition model of point bar in humid environment, which mainly includes lateral accretion sand body and lateral accretion muddy layer (according to Xue 1991)

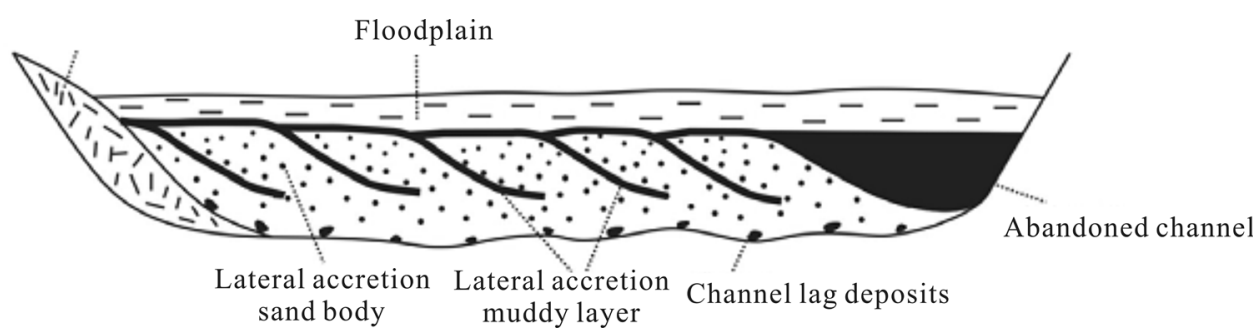




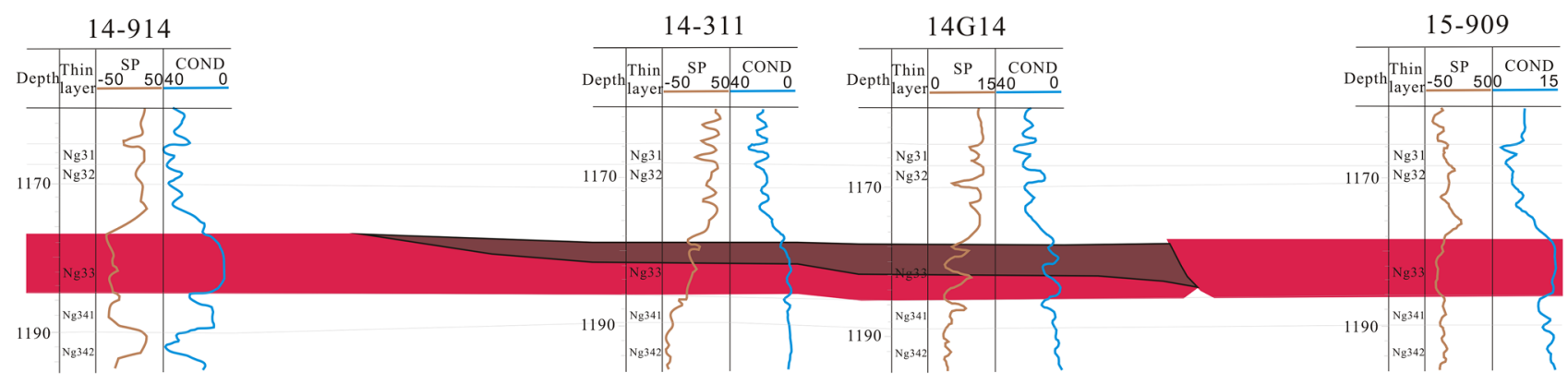

a

$14 \mathrm{XN} 13$

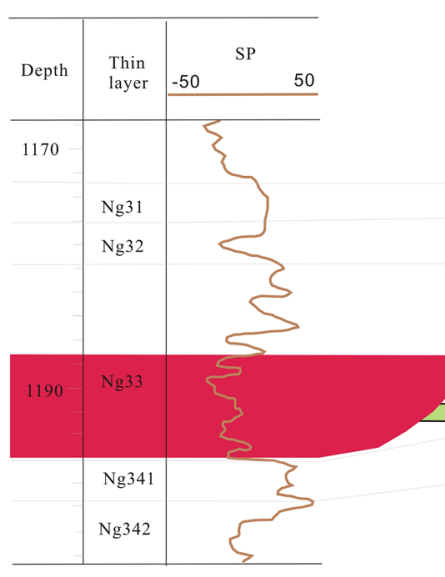

$16 \times 322$
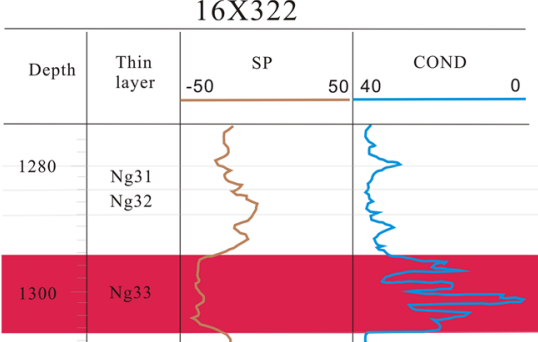

$\left|\begin{array}{l|l}\mathrm{N} g 341 \\ \mathrm{Ng} 342\end{array}\right|\{$
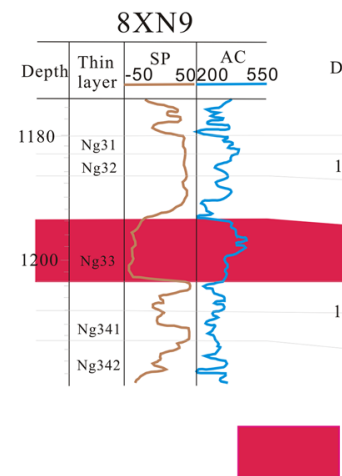

Channel
$14-13$

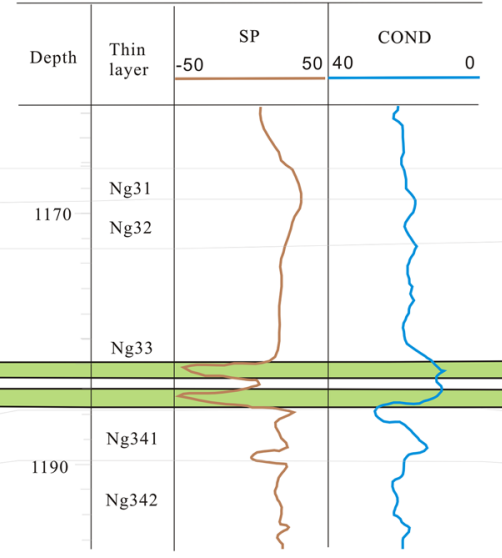

$1190|\underset{N g 334}{\mathrm{Ng} 342}|\}$

Fig. 4 Four types of single channel belt division signs. a Abandoned channel: final phase of abandoned channel represents the boundary of channel. b Discontinuous deposition between channels. c Height b

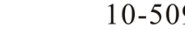

$10-509$

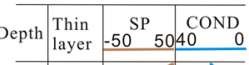

Ng31

$14-413$

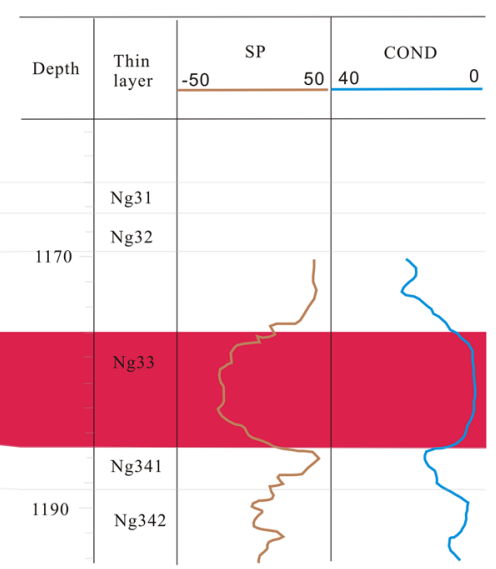

$17 \times 502$

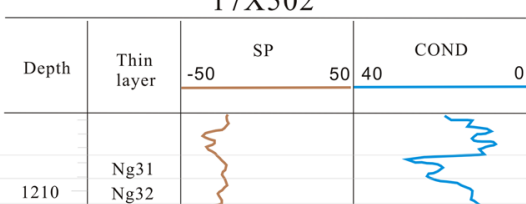

1230

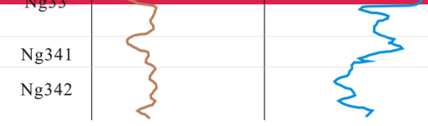

$11-705$

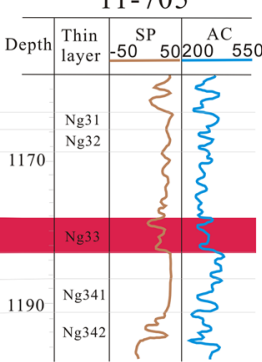

d

Abandoned channel

differences in top surface of channel. d Size differences in channel sand body in a wide range 


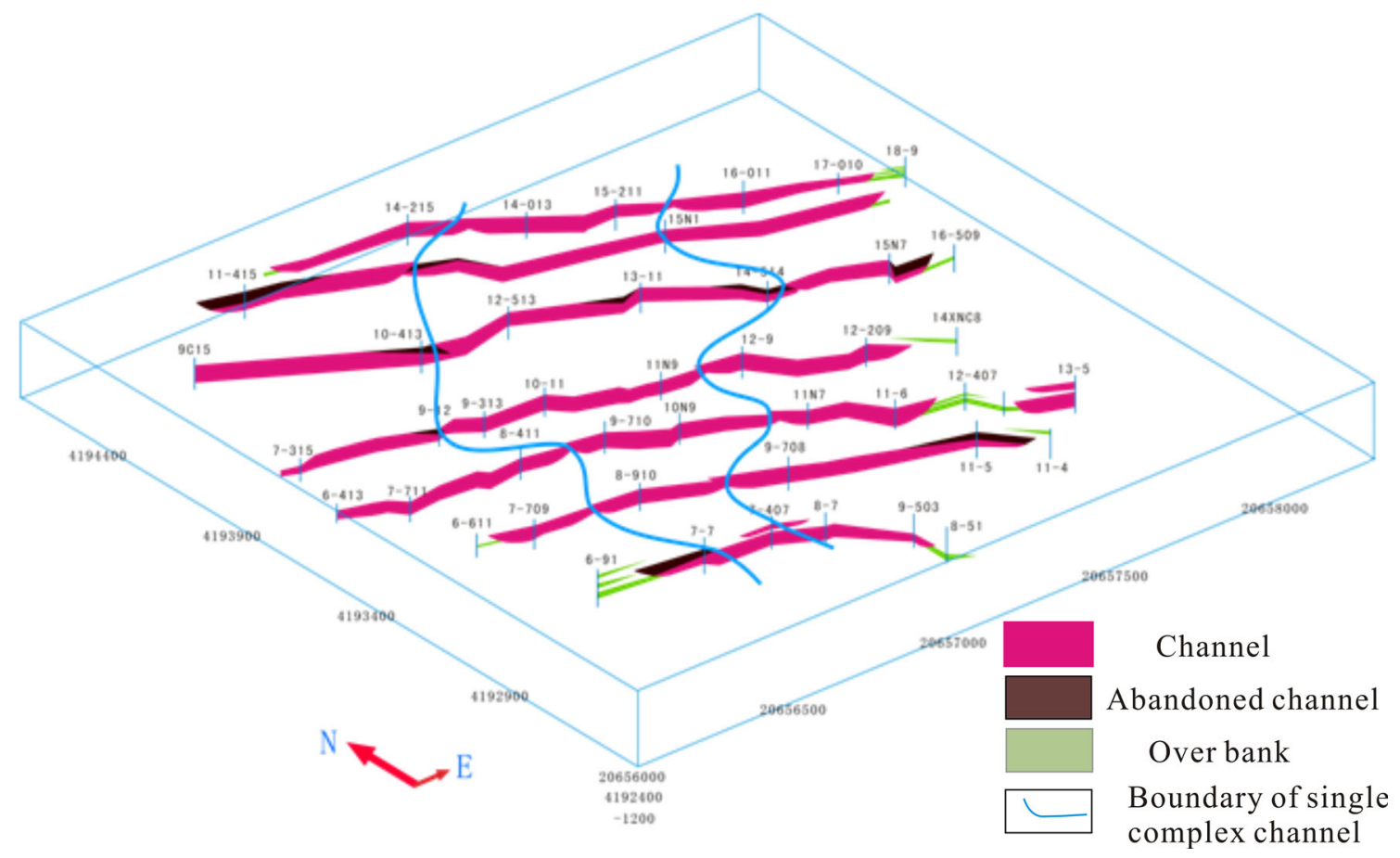

Fig. 5 Division results of single channel belt in $\mathrm{Ng} 33$ thin layer according to the four division signs found in the area

belt division signatures are identified (Fig. 4), and single channel belts are divided in the study area (Fig. 5).

Abandoned channel: The abandoned channel is an important marker of the single channel boundary (Fig. 4a). Within the meandering river belt, the abandoned channel represents the end of a point bar, and the final phase of the abandoned channel represents river diversion. Thus, the final phase of the abandoned channel can be used to distinguish different single channel belts.

Discontinuous deposition between channels: It often develops over bank sediments in the process of river diversion. The discontinuous distribution sand body along the single meandering river belt can be used as single channel boundary division (Fig. 4b).

Top surface height differences of channel: Normally, single channels of several different periods develop at the same time. There is a small difference in the formation time of the different stages of single channels, which leads to the difference in relative distance between top surface of the channel sand body and top of the formation. That means the relative height of the top surface of the channel sand body varies (Fig. 4c).

Size differences in channel sand body: The scale of the river depends on hydrodynamic, ancient landform and other factors, which could lead to thickness differences of the channel sand body. If the thickness difference exists over a wide range in the study area, it can be used as single channel boundary (Fig. 4d).

\section{Single point bar identification}

The complex meandering river belt is composed of several single channel belts. A single channel belt consists of multiple point bars. According to the development situation of the oil field, analysis of deeper single channel belt levels, i.e., the identification of point bars within the single channel belt, is necessary.

The characteristics of the point bar in the single channel belt include three aspects: the vertical sedimentary sequence has a positive rhythm and the sand body thickness is relatively large and adjacent to the abandoned channel. The point bar is the main part of the meandering river sand body, formed due to concave bank erosion and convex bank deposition. The vertically upward rhythm is typical positive, composed of a lateral accretion sand body and a lateral accretion muddy layer. The concave bank erosion and convex bank deposition processes imply that the point bar sand body is the thickest deposition body within the single meandering river belt. This body generally has a lens shape; thus, the thickness variation can be used to determine the point bar distribution. Along with the lateral accretion process, the river curvature increases and at last forms the abandoned channel. From the formation process of the point bar, we can conclude that the abandoned channel represents the end of river sedimentation. Hence, the identification of the abandoned channel is an important tool to distinguish the point bar (Fig. 6). Guided 


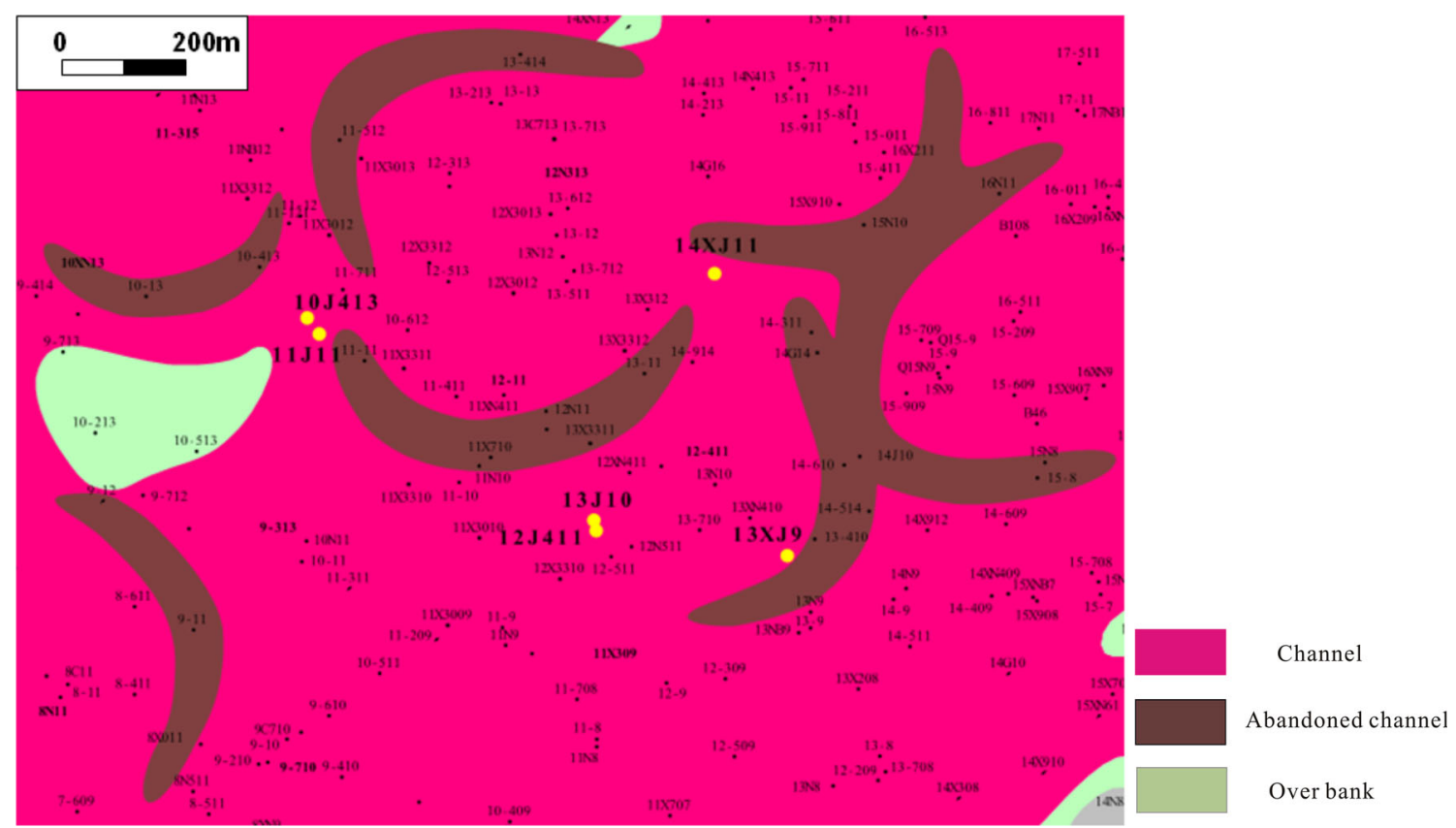

Fig. 6 Single point bar identification in channel belt: abandoned channel represents distribution of point bar

by above-mentioned characteristics, the point bar has been identified.

\section{Anatomy of the inner point bar}

Based on single the point bar identification, inner architecture analysis of the point bar was conducted, which primarily analyzes the distribution of lateral accretion sand body and lateral accretion layer inside the point bar. In the actual analysis, a quantity model of lateral accretion sand body and muddy layers in the point bar is used as a guide and the point bar is characterized using the well data in the study area (Fig. 7).

The dip direction of lateral accretion layer: From the modern sedimentation pattern, it can be observed that the lateral accretion layer of the point bar is always pointed toward the abandoned channel. In this research, the dip of the lateral accretion layer has been determined primarily on the basis of the lateral accretion process of the point bar. The lateral accretion layer is always tilted toward the abandoned channel.

The dip angle of lateral accretion layer: The lateral inclination angle ranges from $5^{\circ}$ to $8^{\circ}$ according to the

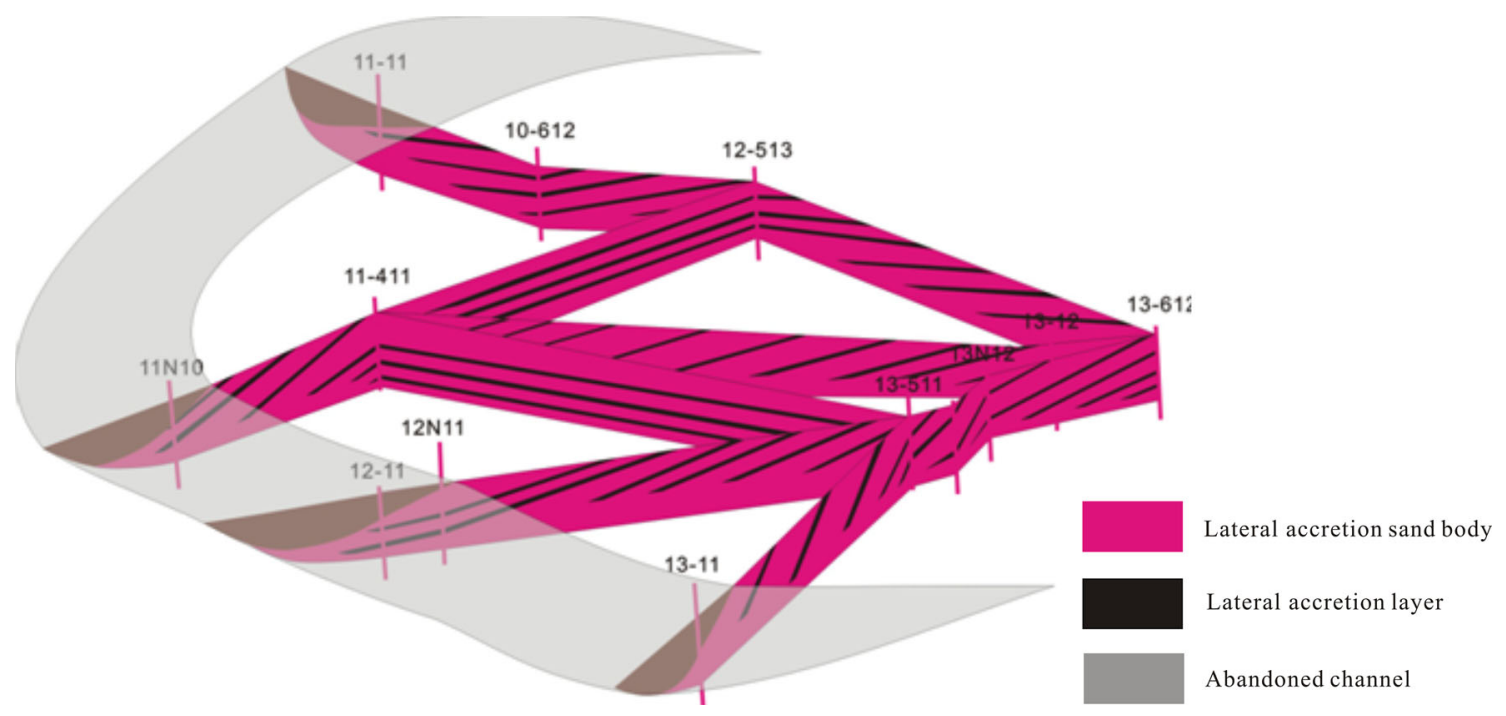

Fig. 7 Anatomy of inner point bar using well data and quantity model of point bar 


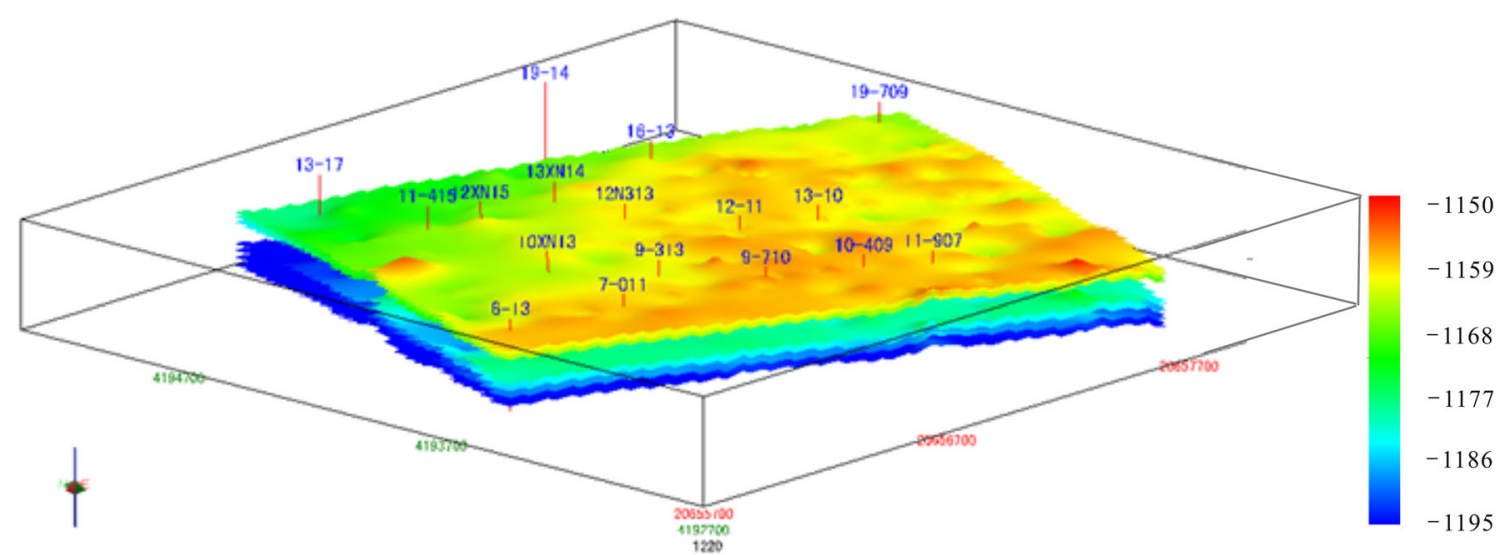

Fig. 8 Structure model of $\mathrm{Ng} 3$ sand group in the study area

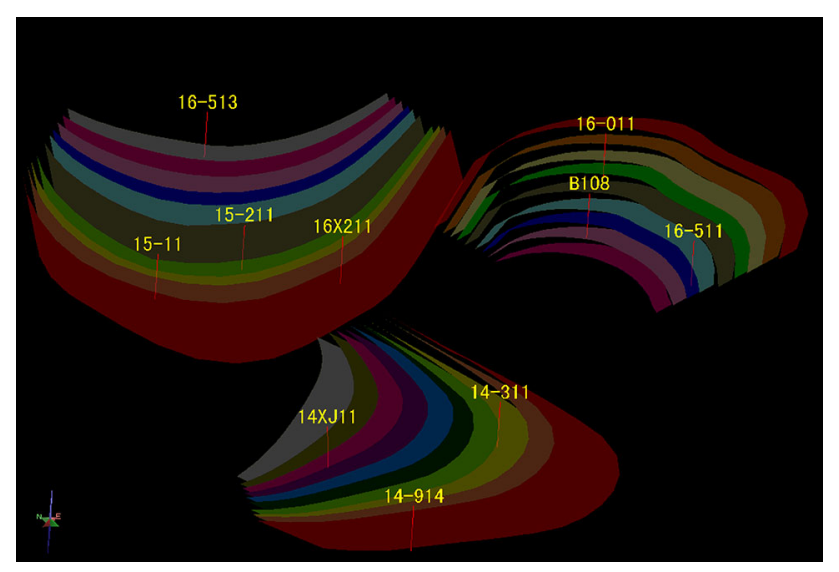

empirical formula for river width/depth ratio and lateral accretion dip angle (Zhou et al. 2009).

The plane distance of the lateral accretion layer: The vertical thickness of the single lateral accretion sand body ranges from 2 to $3 \mathrm{~m}$. Based on the inclination angle data, the plane distance of the lateral accretion layer ranges from 20 to $35 \mathrm{~m}$.

The horizontal width of the single lateral accretion sand body: According to the empirical formula by Leeder (1973), the width between river banks in the study area was determined to be $\sim 110-230 \mathrm{~m}$ and the horizontal width of the single lateral accretion sand body is approximately $2 / 3$ of the full width of the river, ranging from 55 to $120 \mathrm{~m}$.

Fig. 9 Establishment of 3D lateral accretion surface model combined with well data

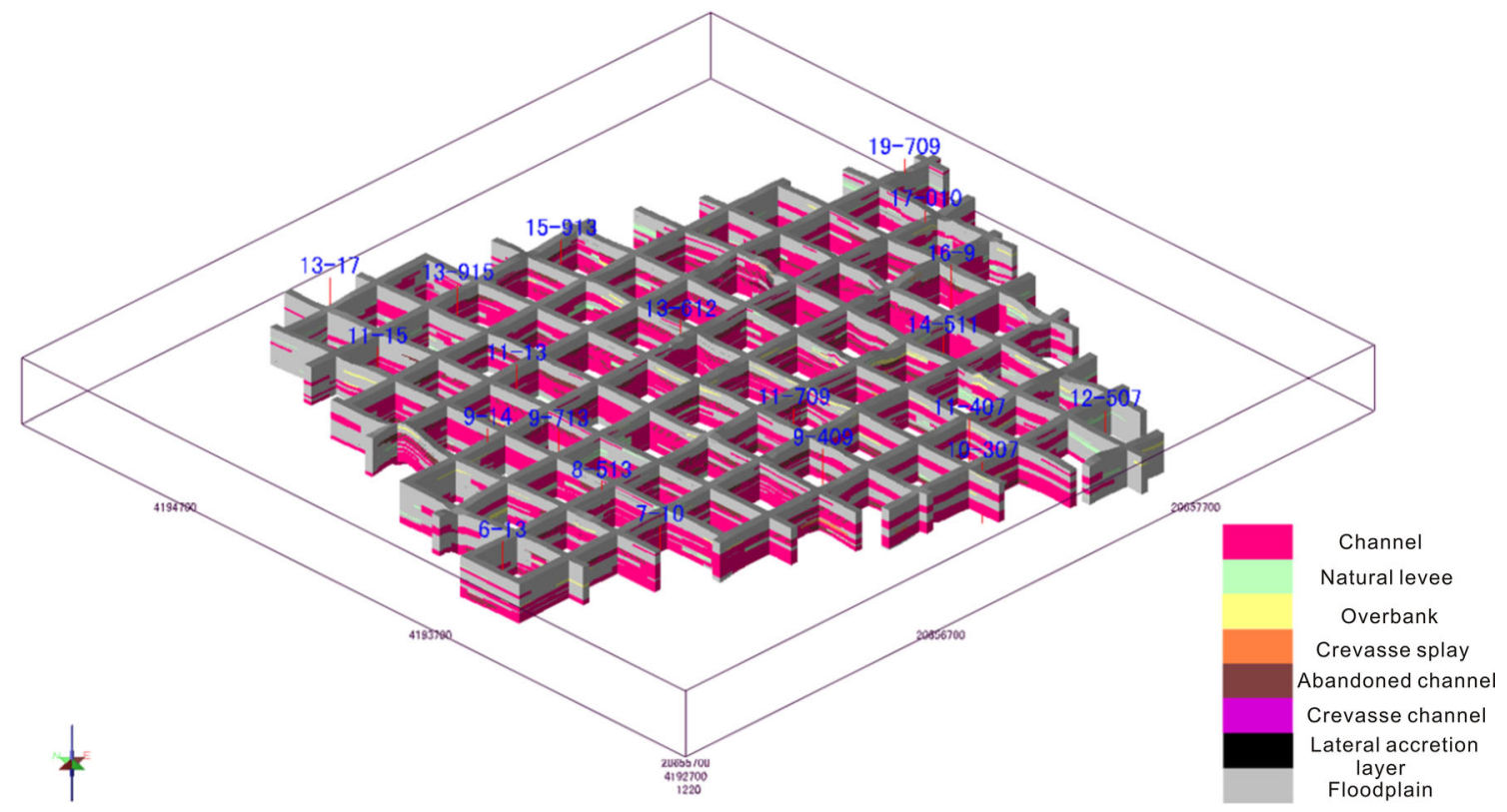

Fig. 10 Three-dimensional grid chart of architecture model in $\mathrm{Ng} 33$ thin layer 


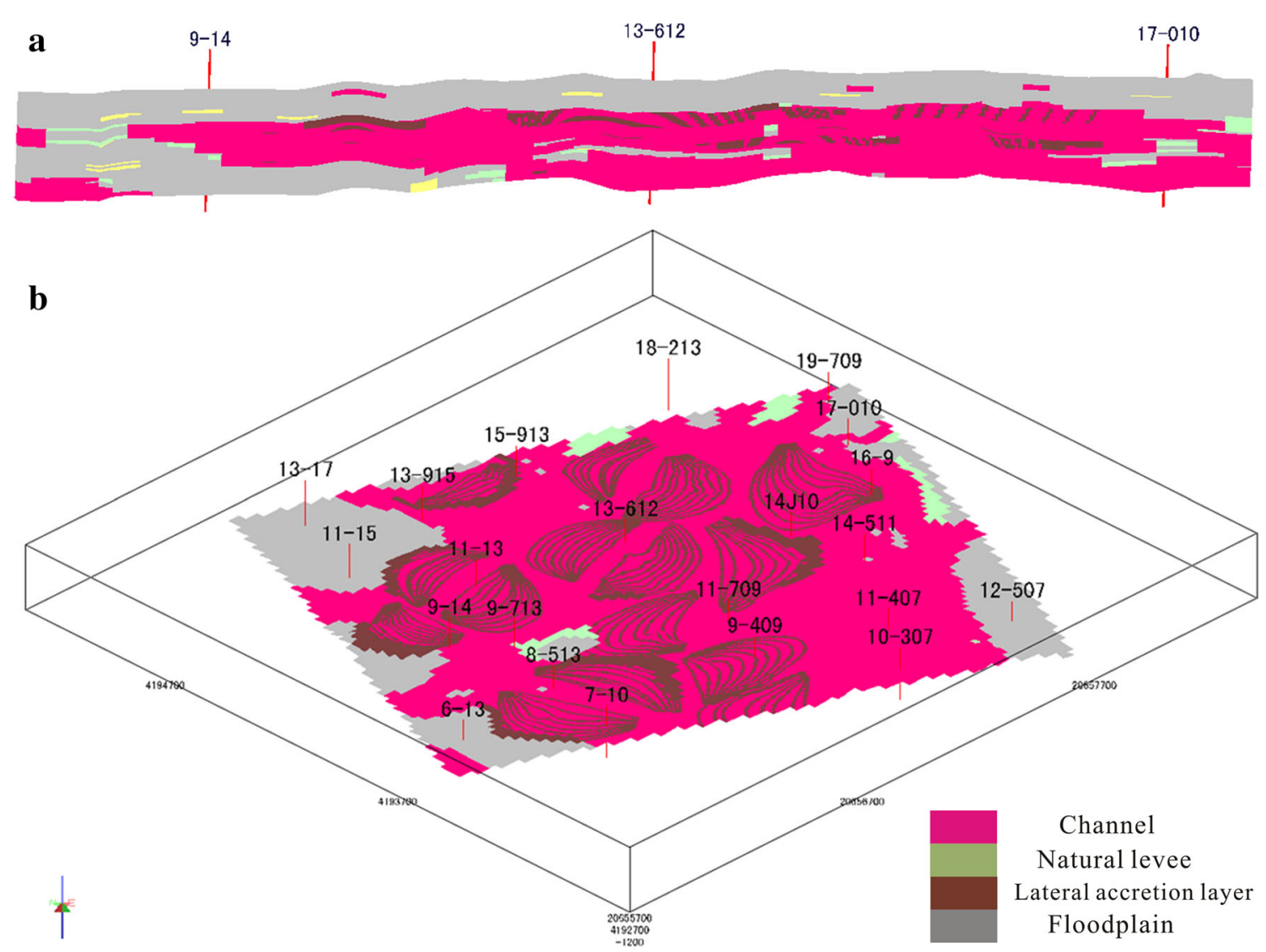

Fig. 11 a Section map of architecture model in Ng33 thin layer. b Plane map of architecture model in $\mathrm{Ng} 33$ thin layer

\section{$3 D$ architecture modeling}

Three-dimensional reservoir modeling is important for the prediction of remaining oil distribution in the late stage of oil field development and can provide accurate geological models for reservoir numerical simulation and remaining oil distribution forecast. Compared with traditional 3D geological models, the reservoir architecture model not only reflects complex sand body distribution in three-dimensional space but also indicates spatial distribution characteristics of inner architecture elements, such as the lateral accretion muddy layer inside the point bar. Based on data preparation and architecture research in the study area, 3D structure model, 3D architecture model and 3D reservoir parameter model have been established, respectively.

\section{Structure model}

The structure model is the basis of the 3D reservoir geological model. It reflects the reservoir framework, which generally includes fault model, formation surface model and stratum model. There exists no fault in the study area; thus, only formation surface model and stratum model are needed. The structural model of the $\mathrm{Ng} 3$ sand group is obtained using the radial basis function interpolation method. As requirement of the internal architecture model of the point bar, the grid size is set to $20 \mathrm{~m} \times 20 \mathrm{~m} \times 0.2 \mathrm{~m}$ (Fig. 8).

\section{Reservoir architecture model}

In the architecture modeling process, different levels of architecture unit models are established based on the idea of hierarchical modeling, which includes complex channel belt model, single channel belt model and inner point bar model. The development of a lateral accretion layer model is the key process in reservoir modeling. In this study, the embedded 3D geological modeling method is used to establish the lateral accretion layer model. In a first step, a 3D lateral accretion surface model is automatically set up in combination with the well data (Fig. 9). Next, the grid of the point bar development area is encrypted and the grid, which passes through the lateral accretion surface, is assigned to the lateral accretion muddy layer, which has no permeability. As a result, an internal three-dimensional model of the inner point bar is created. In this study, we use sequential indicator simulation to establish the reservoir architecture model. Reservoir architecture is a discrete variable. Sequential 


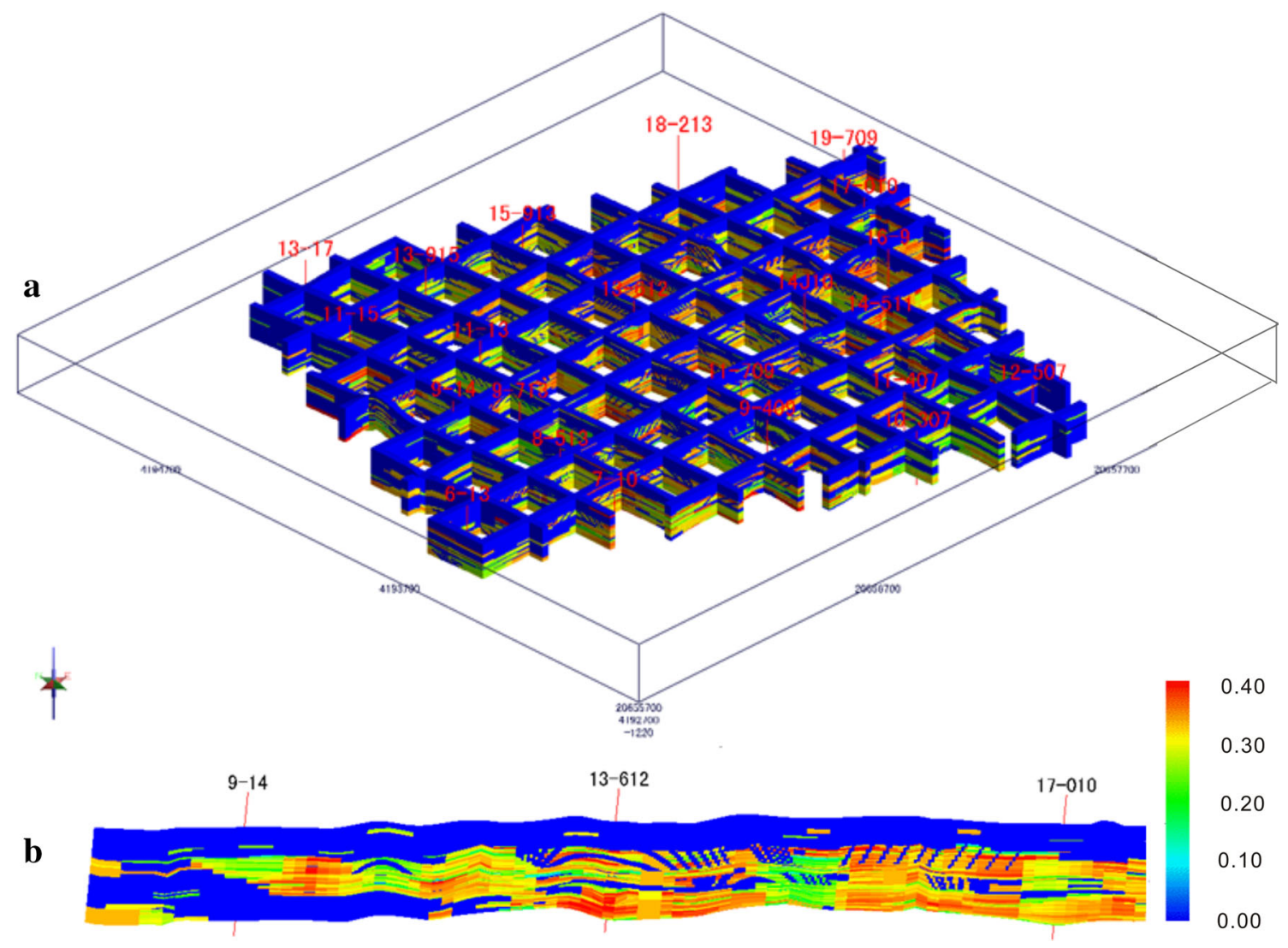

Fig. 12 a Three-dimensional grid chart of porosity model constraint by architecture model in $\mathrm{Ng} 33$ thin layer. b Section map of porosity model in $\mathrm{Ng} 33$ thin layer

indicator simulation can better predict complex geological phenomena. However, it has some limitations with respect to geometrical shape of the target. Thus, sequential indicator simulation is combined with artificial interaction to modify the architecture model of the reservoir. The architecture model is shown in Figs. 10 and 11.

\section{Reservoir parameter model}

Based on the architecture model established above and well logging data, the reservoir parameter model is built. A sequential Gaussian modeling algorithm is used to calculate a three-dimensional porosity and permeability model of the $\mathrm{Ng} 3$ sand group in the study area, which fully reflects the distribution characteristics of meandering river reservoir parameters in 3D space and provides an accurate geological numerical simulation (Fig. 12a, b).

\section{Conclusions}

The analysis of meandering river deposition architecture can be divided into three levels based on hierarchy analysis, which include complex meandering river belt, single meandering river belt, single point bar and inner point bar. The classification method of the single meandering river belt has been summarized, and the single channel belt boundary has been identified in the study area. Furthermore, deposition architecture of the inner point bar has been studied, and three-dimensional deposition patterns have been obtained. Based on architecture analysis, reservoir architecture model, a lateral accretion plane model and a 3D lateral accretion muddy layer model of the inner point bar have been established. The reservoir parameter model has been calculated within reservoir architecture model constraints to enable the application of deposition architecture analysis for reservoir assessment and development.

Acknowledgements This research was funded by the National Science and Technology Major Project (No. 2011ZX05009-003) in China. We gratefully thank Shengli Oil field Corp of Sinopec for supplying researching data and for permission to publish this paper. We also thank anonymous reviewers for their comments.

Open Access This article is distributed under the terms of the Creative Commons Attribution 4.0 International License (http:// creativecommons.org/licenses/by/4.0/), which permits unrestricted use, distribution, and reproduction in any medium, provided you give appropriate credit to the original author(s) and the source, provide a link to the Creative Commons license, and indicate if changes were made. 


\section{References}

Allen JRL (1983) Studies in fluviatile sedimentation: bars, bar complexes and sandstone sheets (lower sinuosity braided streams) in the Brownstones (L. Devonian), Welsh Borders. Sediment Geol 33(4):237-293

Gibling MR (2006) Width and thickness of fluvial channel bodies and valley fills in the geological record: a literature compilation and classification. J Sediment Res 76(5):731-771

Jiao YQ, Yan JX, Li ST (2005) Architectural units and heterogeneity of channel reservoirs in the Karamay Formation, outcrop area of Karamay oil field, Junggar basin, northwest China. AAPG Bull 89(4):529-545

Leeder MR (1973) Fluviatile fining upwards cycles and the magnitude of paleochannels. Geol Mag 110(3):265-276

Li SY, Li Z, Yue SC (2002) The study of depositional model in the upper member of Guantao Formation in Gudao Oilfield of Shengli petroleum area. Chin J Geol 37(2):219-230

Lorenz JC, Heinze DM, Clark JA (1985) Determination of width of meander-belt sandstone reservoirs from vertical downhole data, Mesaverde Group, Piceance Greek Basin, Colorado. AAPG Bull 69(5):710-721

Makaske B, Weerts HJT (2005) Muddy lateral accretion and low stream power in a sub-recent confined channel belt, RhineMeuse delta, central Netherlands. Sedimentology 52(3):651-668

Matthew JP, Marielis FV, Thomas LD (2008) Characterization and 3D reservoir modeling of fluvial sandstones of the Williams Fork Formation, Rulison Field, Piceance Basin, Colorado, USA. J Geophys Eng 5(2):158-172
Miall AD (1985) Architectural-element analysis: a new method of facies analysis applied to fluvial deposits. Earth Sci Rev 22(4):261-308

Miall AD (1988) Architectural Elements and Bounding Surfaces in Fluvial Deposits: anatomy of the Kayenta Formation (Lower Jurassic), Southwest Colorado. Sediment Geol 55(3-4):233-262

Miall AD (1996) The geology of fluvial deposits: sedimentary facies, basin analysis and petroleum geology. Springer, Berlin

Qiu YN, Xue SH (2001) Oil and gas reservoir evaluation technique. Petroleum Industry Press, Beijing

Richard L, Jones RR (2007) Characterization of fluvial architectural elements using a three-dimensional outcrop data set: Escanilla braided system, South-Central Pyrenees, Spain. Geosphere 3(6):422-434

Schumm SA, Rigby JK, Hamblin WK (1972) Recognition of ancient sedimentary environments in fluvial paleochannels. SEPM Spec Publ 16:98-107

Su QL, Zhang BH, Mao WR (2009) Technical measures and effects of enhanced oil recovery in special high water cut stage in Gudao oilfield. Oil Gas Geol Recovery 5:52-55

Weber KJ, Hans D (1999) Screening criteria to evaluate the development potential of remaining oil in mature fields. SPEREE 2(5):405-411

Wu YY, Wu SH, Cai ZQ (2005) Oilfield geology (the, 3rd edn. Petroleum Industry Press, Beijing

Xue PH (1991) Introduction of reservoir patterns of point bar. Petroleum Industry Press, Beijing

Zhou YB, Wu SH, Yue DL (2009) Controlling factor analysis and identification method of lateral accretion shale beddings angle in point bar. J China Univ Pet (Ed Nat Sci) 33(2):7-11 